\title{
Inclusão escolar: a perspectiva das mães de alunos com Síndrome de Down
}

\author{
Luciane Najar Smeha* \\ Véra Lúcia Pacheco de Oliveira**
}

\section{Resumo}

A pesquisa objetivou conhecer a percepção das mães sobre a vida escolar do filho com síndrome de Down. Procurou identificar sentimentos, conhecer vivências e fatores que contribuem ou dificultam o processo de inclusão no sistema público regular em Santa Maria, RS. Foi realizada uma pesquisa qualitativa, com a participação de cinco mães. Os dados coletados em entrevista semiestruturada foram analisados com base em Bardin. Três categorias finais emergiram: a busca pela inclusão do filho com Síndrome de Down; a fragilidade da inclusão na rede regular de ensino; as contribuições e dificuldades do processo de inclusão nas escolas regulares. Resultados apontam que as disparidades entre o que está posto como ideal e o que se realiza na prática fazem com que as mães percebam o processo ineficiente e nocivo à saúde mental dos filhos. Vivências perturbadoras são provocadas pela não observação daquilo que se acha posto em termos de leis e preceitos inclusivos, despertando, nas mães, sentimentos de mágoa, tristeza, e frustração. A lei de inclusão diz da obrigação em aceitar todas as crianças sem distinção, porém não estabelece de que forma, oportunizando a cada contexto incluir, levando em conta suas especificidades, o que torna cada experiência muito singular. Uma solução única é difícil apontar, pois a escola se constituiu e ainda se mantém como uma instituição excludente. Entretanto, incluir a criança com Síndrome de Down, passa pelo compromisso de descobrir e organizar ações que respondam de maneira adequada às necessidades dessa população.

Palavras-chave: Maternidades; Inclusão escolar; Síndrome de Down.

\footnotetext{
* Professora Doutora do Centro Universitário Franciscano (UNIFRA), Santa Maria, Rio Grande do Sul, Brasil.

** Psicóloga graduada pelo Centro Universitário Franciscano (UNIFRA), Santa Maria, Rio Grande do Sul, Brasil.
} 


\section{School inclusion: the perspective of mothers of students with Down Syndrome}

\section{Abstract}

The research aimed to know the perception of the parents on the pertaining to school life of their child with Down syndrome. Its objective was to identify feelings, to know experiences and factors that contribute or make the process difficult, bringing in the problematic of inclusion in regular public system of Santa Maria, Rio Grande do Sul. A qualitative research, with five mothers, was carried through. The data collected in semistructuralized interview had been analyzed based on Bardin (2002). Three final categories had emerged: the search for the inclusion of the child with Down syndrome; the fragility of the inclusion in the regular education net; the contributions and difficulties of the inclusion process in regular schools. Results point that the disparities between what it is ranked as ideal and what it carries through in the practical way is seen by mothers as an inefficient and harmful process to the mental health of children. Disturbing experiences are provoked by the lack of observation of what can be found in the inclusive rank of laws and rules, making the mothers feel hurt, sadness, and frustration. The inclusion law shows that there's an obligation in accepting all the children without distinction, however, it does not show the ways to make it possible, or how to include each context, taking into account its especificities, what makes each experience singular. A single solution is difficult to point out, since the school was constituted, and still remains, as an exculpatory institution. However, the task to include the child with Down syndrome passes for the commitment to discover and organize actions to solve, in an adequate way, the people's expectations. Keywords: Mothers; School Inclusion; Down syndrome.

\section{Introdução}

A construção social sobre a deficiência intelectual sempre obedeceu a uma lógica excludente, alicerçada na separação de alunos de acordo com suas diferenças, isto é, normais e anormais, fortes e fracos, as crianças com alguma dificuldade de aprendizagem ou com desenvolvimento atípico eram afastadas da escola (KASSAR, 2011). Na década de 1990, na Tailândia, a visão estreita do preconceito começou a se alargar, culminando, em 1994, com a Declaração de Salamanca. Esse evento foi de grande importância no sentido de convidar chefes de estado para o comprometimento, abertura e fortalecimento das concepções inclusivas, uma vez que a filosofia forte que se estabeleceu nesse encontro foi de que "todas as crianças devem aprender juntas, sempre que possível, independentemente de quaisquer dificuldades ou diferenças que elas possam ter" (DECLARAÇÃO DE SALAMANCA, 1994, p. 4). Em decorrência, a política educacional atual, propõe como estratégia para a inclusão: matricular todas as crianças em classes comuns da rede regular de ensino, além de oferecer atendimento educacional especializado para complementar ou suplementar a escolaridade. 
A articulação dessa política educacional, baseada no respeito à diferença do outro, trouxe a expectativa de uma nova era. Entretanto, um olhar crítico precisa ainda estar debruçado sobre esses direitos, pois, é importante pensar que, "mesmo sob a garantia da lei, podemos encaminhar o conceito de diferença para a vala dos preconceitos, da discriminação, da exclusão" (MANTOAN, 2006, p. 25). Na busca pela superação das desigualdades, kassar (2012) aponta que, a identificação das diferenças ainda é percebida como algo extraordinário e não como características constitutivas de uma população. De acordo com a autora a incorporação e efetivação dos direitos das pessoas com deficiência é um avanço, mas é necessário considerar que há limites, entre eles, está a oferta de uma única forma de atendimento às pessoas com deficiência, na medida em que, há restrições de investimentos em espaços especializados em função dos elevados custos para os cofres públicos.

Nesse aspecto, Pires (2008) considera que o sucesso do processo de inclusão está em aceitar a diversidade que se apresenta no cotidiano escolar, devendo a escola, como parte integrante desse sistema, adaptar-se às necessidades educacionais de todas as crianças. Outro autor que se posiciona a respeito do novo paradigma inclusivo no Brasil é Carvalho (2008, p. 43). Ele aponta que "é reconhecido que o sistema educativo nacional ainda não cumpre o conjunto de requisitos que assegurem e garantam aos educandos, especialmente aos alunos com uma condição de deficiência, a fruição do sucesso educativo".

Ainda, sobre essa ótica, Castro e Freitas (2008) afirmam que é dentro do espaço educacional, no convívio com as diferenças, que se conduz a descoberta e o estabelecimento de relações positivas ou negativas, dependendo dos paradigmas adotados. Eles apontam que o mais importante de tudo é pensar, discutir e debater as questões relativas à diversidade. No entanto, considerando a recente realidade inclusiva que se estabeleceu no cenário mundial, ainda não é possível conhecer resultados que amparem, de forma definitiva, as implicações que a inclusão traz, principalmente no que diz respeito à construção subjetiva da criança com deficiência, inclusa no sistema regular, pois a capacidade de interação nas crianças, com ou sem deficiência, varia conforme a singularidade e as condições que o grupo oferece a ela (SMEHA; SEMINOTTI, 2008).

Ao defender a inclusão, Mantoan (2006) se coloca contra a naturalização de representações discriminatórias e diz que podemos considerar os pais como grandes aliados na reconstrução da escola brasileira, sendo eles a força estimuladora e reivindicadora, que exige o melhor para seus filhos. Pensar, portanto, os pais como sujeitos que vivenciam esse processo juntamente com seu filho Down, faz deles articuladores e mediadores indispensáveis para se conhecer essa realidade.

A partir do exposto, esta pesquisa objetivou identificar a percepção dos pais sobre a vida escolar do filho com síndrome de Down, conhecer suas vivências, seus sentimentos e os fatores que contribuem ou dificultam esse processo, trazendo para discussão esse sistema que, por vezes, pode se apresentar como excludente. 


\section{Metodologia}

Para realização do estudo, foi utilizado o método qualitativo (MINAYO, 2008). Participaram desta pesquisa cinco mães, associadas da Bem Viver - Associação de Pais e Familiares do Down, com sede na cidade de Santa Maria, RS - escolhidas por conveniência (GIL, 2006).

Frente à necessidade de identificar as mães sem, contudo, expor suas identidades, foram utilizadas para nomeá-las, no corpo da pesquisa, as siglas: P1, P2, P3, P4, e $\mathrm{P} 5$, levando-se em consideração a sequência em que foram entrevistadas. No quadro um, concentram-se informações que caracterizam a realidade dos participantes do estudo.

Quadro 1: Informações complementares

\begin{tabular}{|c|c|c|c|c|c|c|c|c|}
\hline $\begin{array}{c}\text { Identifi- } \\
\text { cação }\end{array}$ & Idade & Profissão & $\begin{array}{c}\text { № } \\
\text { Filhos }\end{array}$ & $\begin{array}{c}\text { Idade } \\
\text { do Filho } \\
\text { Com SD }\end{array}$ & $\begin{array}{c}\text { Tempo de } \\
\text { Perma- } \\
\text { nencia na } \\
\text { Escola }\end{array}$ & $\begin{array}{c}\text { Tempo } \\
\text { que se } \\
\text { Encontra } \\
\text { fora da } \\
\text { Escola }\end{array}$ & $\begin{array}{c}\text { Tipo de } \\
\text { Escola }\end{array}$ & $\begin{array}{c}\text { Situação } \\
\text { Atual }\end{array}$ \\
\hline P1 & 50 & Professora & 02 & 11 anos & 08 anos & - & Municipal & Incluído \\
\hline P2 & 40 & $\begin{array}{c}\text { Gerente de } \\
\text { Operações }\end{array}$ & 01 & 09 anos & 06 anos & - & Estadual & Incluído \\
\hline P3 & 45 & $\begin{array}{c}\text { Técnica em } \\
\text { Enferma- } \\
\text { gem }\end{array}$ & 02 & 11 anos & 07 anos & 01 ano & - & $\begin{array}{c}\text { Não } \\
\text { Incluído }\end{array}$ \\
\hline P4 & 53 & $\begin{array}{c}\text { Professora } \\
\text { P5 }\end{array}$ & 02 & 16 anos & 10 anos & - & Estadual & Incluído \\
\hline & $\begin{array}{c}\text { Técnica em } \\
\text { Enferma- } \\
\text { gem }\end{array}$ & 02 & 17 anos & 06 anos & 05 anos & & $\begin{array}{c}\text { Não } \\
\text { Incluído }\end{array}$ \\
\hline
\end{tabular}

Como instrumento para a coleta de dados, foi utilizada a entrevista semiestruturada, em que cinco questões funcionaram como guia, permitindo as mães responderem, livremente, sobre suas vivências, sentimentos, expectativas, favorecimentos e dificuldades do processo inclusivo. No procedimento para a coleta de dados, observou-se a disponibilidade das mães. Quatro delas foram entrevistadas em seu ambiente domiciliar, e uma no local de trabalho, no final de outubro de 2009. A saída do campo de pesquisa foi ocasionada pela saturação dos dados.

Para tratamento dos dados, optou-se pela Análise de Conteúdo de Bardin (2002). Procedeu-se a pré-análise, etapa de organização dos dados; leitura flutuante da qual emergiram impressões e hipóteses, e escolha de partes da narrativa segundo critérios de pertinência. Emergiram três categorias temáticas finais: a busca pela inclusão do filho com síndrome de Down; a fragilidade da inclusão na rede regular de ensino; as contribuições e dificuldades do processo de inclusão nas escolas regulares. 
A pesquisa foi submetida à avaliação do Comitê de Ética do Centro Universitário Franciscano e aprovada segundo registro CEP/Unifra: 290.2009.3.

\section{Apresentação e discussão dos resultados}

\section{I - A busca pela Inclusão do filho com síndrome de Down}

A escola surge, na vida da criança, como o primeiro ambiente socializador externo. É lá que a criança vai dar continuidade ao processo iniciado no seu mundo familiar. Percebendo a importância do papel que a escola exerce na vida do filho, todas as mães participantes relataram que a primeira experiência escolar inclusiva do filho com síndrome de Down deu-se em instituição particular. Torna-se pertinente desenvolver um pouco mais sobre isso, procurando entender o desejo das mães em privilegiar essa modalidade de instituição para o início da vida escolar de seus filhos.

As razões que sinalizam as motivações por alternativas que, de certa forma, possam abrandar suas angústias e dificuldades no caminho da inclusão, vêm possivelmente da crença de que escolas particulares possuem maior qualidade em suas práticas educativas. Apostar nesse pensamento, portanto, é sonhar com um dispositivo capaz de ajudar os filhos a inserir-se em um lugar mais favorável ao seu desenvolvimento escolar. Essa escolha das mães por escolas mais estruturadas, encontrase amparada por Mantoan (1992). Segundo ela, indivíduos com deficiência mental e lentidão intelectual reagem mais satisfatoriamente quando há uma ação educativa mais eficiente e adequada para estruturar condutas que, em crianças sem deficiência, aparecem espontaneamente. Uma educação de qualidade, que atenda às necessidades educativas especiais desse grupo é fundamental, pois a síndrome de Down traz como característica mais freqüente a deficiência intelectuall (VOIVODIC, 2004).

Assim, ao tentar incluir seus filhos em outro ambiente que não o familiar, os pais se dão conta das dificuldades que se apresentam. Suas escolhas ficam "impostas àquilo que a modernidade inventou que é a norma, aquele princípio geral que a todos quer atingir e que divide todos em dois grupos: os que estão dentro do normal e os que estão fora do normal" (VEIGA NETO, 2005, p. 62). No decorrer dessa busca, as mães descobrem a realidade que o discurso inclusivo não alcança, mas que estão ilustradas no fragmento abaixo:

[...] mesmo tu pagando tu não consegue um espaço para eles! Até particular as professoras dizem: Mas eu nunca trabalhei com pessoas com síndrome de Down! No momento não temos vaga! No momento não temos vaga! Então fica muito difícil a gente não sabe o que faze com os nossos filhos. (P5)

Nessa tarefa de buscar um espaço acolhedor para o desenvolvimento educacional dos filhos, desde logo, se faz necessário desfazer idealizações, pois, entre a inclusão que desejamos e a que é possível, muitas vezes encontramos abismos que parecem intransponíveis (EMÍLIO; CINTRA, 2008). A compreensão das mães de que, no contexto escolar inclusivo, a diferença ainda é vista como algo indesejável, incomum, anormal, desfaz suas fantasias sobre a existência de escolas regulares ideais, despertando sentimentos de frustração, tristeza e desânimo.

Revista Educação Especial | v. 27 | n. 49 | p. 403-416| maio/ago. 2014

Santa Maria 


\section{II - A fragilidade da inclusão na rede regular de ensino}

A fragilidade do processo inclusivo vem sendo apontada por diversos autores. Não há equívocos quanto ao profundo desencontro existente entre a intenção do Estado, expressa em documentos oficiais, e a realidade educacional de alunos com deficiência (CUNHA, 1989). Como um eco a essas palavras, Omote (2001) diz que as práticas educativas inclusivas vêm apresentando disparidade crônica, entre a intenção e a realidade. Essas ideias são reafirmadas na fala da mãe de um pré-adolescente com síndrome de Down:

E que a inclusão, a inclusão, ela tem que ser bem feita, as autoridades tem que fazer bem feita, ou é melhor não fazer! È melhor não existir, só para dizer que tem. Que é o que ele seria então, nessa escola? Um decorativo, na sala de aula? Simplesmente colocado lá, para dizer que estão fazendo inclusão? (Pl)

Nessa manifestação, a mãe mostra insatisfação diante de uma inclusão que não atende as necessidades do aluno. $\mathrm{O}$ ato de incluir todas as crianças nas escolas passa pela observação da ética e da justiça, não podendo a inclusão significar, somente, a colocação de crianças com deficiência no interior da escola (MANTOAN, 2004). As explicações para a fragilidade das propostas inclusivas narradas pelas mães são referidas por Santos e Mendes (2005 p. 133): "o fato de abrirmos as portas da escola para a criança com deficiência não significa que transformações ocorrerão, seja no espaço físico, seja principalmente na mudança de concepção da instituição, incluindo diretores, professores, apoio técnico". Assim, cabe salientar que a eficácia do processo de inclusão depende de diversos e complexos fatores, entre eles, uma mudança de paradigma, ampliação recursos financeiros e qualificação de recursos humanos.

A falta de coerência entre o discurso da política e a prática nas escolas, retira das mães as certezas, elas ficam sem parâmetros para agir. Atentas ao que acontece dentro do processo, não sabem o que pensar: "O que é certo? O que é errado? Estão dizendo uma coisa, tu vê, a realidade é outra né? Então tu não sabe, o que tu faz, muitas vezes" (P5). A Lei de inclusão obriga a escola a aceitar todas as crianças sem distinção, porém não sistematiza o processo, o que leva cada instituição agir à sua maneira, levando em conta suas especificidades, mas não às necessidades escolares da criança com síndrome de Down. A fala de uma das participantes retrata essa situação:

É, é bem difícil [...] a gente visitou várias escolas, tanto particulares, como municipais, como estaduais e duma maneira educada ou a professora aceitava e a direção da escola não estava aberta para essa nova proposta, muitas vezes a direção da escola aceitava e a professora da turma não mostrava interesse. (P5)

Esse desencontro de ideias nos diz de uma cultura de segregação ainda existente nos meios inclusivos. É complexa a tentativa de práticas inclusivas em uma sociedade que é ela mesma excludente desde os tempos mais remotos (VEIGA NETO, 2005). A dificuldade de concretizar a proposta de inclusão é mencionada na fala da mãe Pl, ela reflete sobre o preconceito oriundo da própria escola: "[...] fico muito chateada, muito triste [...] a gente sente assim oh, que não existe o interesse, não existe o interesse de saber como é que é" (Pl). 
Ao reportar-se a uma vivência inclusiva, que não deu certo para seu filho, essa mesma mãe diz de outros sentimentos:

[...] um sentimento de ódio, eu não quero nem mesmo enxergar essa escola, é fiquei muito sentida, [...] me magoou muito, que não quis mais saber não! Só fui lá, peguei os documentos dele e nem disse por que, nem me perguntaram, acho que deram Graças a Deus! Não quiseram nem saber por que eu estava retirando ele. Isso também é uma coisa que me magoa né! Por que nem querer saber? Ah, mas o que houve? O que aconteceu? Ele não se adaptou? Nada, ta, nem me perguntaram. (Pl)

Outra participante, falando em complicação e frustração, também narra suas experiências: "[...] é bem complicado, a gente espera que o filho da gente seja bem recebido em tudo que é lugar, mas é frustrante por um lado é frustrante assim, mas eu procuro fazer do limão uma limonada" (P2).

Não acreditando mais em uma solução, uma das mães também demonstra sentimentos de frustração e desamparo, diante das dificuldades encontradas. Cansada pela luta solitária, buscou ajuda de um psiquiatra, que constatou sofrimento psíquico em seu filho como consequência das vivencias somadas ao longo de anos, nos quais houve inúmeras tentativas frustradas de inclusão, na rede regular de ensino. Na época, o filho apresentava sintomas de depressão, síndrome do pânico e ansiedade generalizada.

[...] eu não vou insistir mais, sabe? Por que não adianta, é muito frustrante pra gente! Tu vê o sofrimento, a angústia de uma criança estar num lugar assim, oh, que ela não se sente bem, que ela não está bem, que ele não está incluído, ele ta indo, riscando, porque o que ele trazia nos cadernos era risco, risco, risco, [...] ou então ele ficava uma duas horas, nem duas horas na sala de aula, vai para a sala de recursos lá, ou pra biblioteca, daí sozinho! Que inclusão é essa? [...] (P3)

A inclusão escolar é um processo pelo qual a criança portadora de algum transtorno do desenvolvimento participa das atividades escolares de forma regular. $\mathrm{O}$ currículo deve ser flexível, considerando as potencialidades e limitações individuais de cada criança (STAINBACK; STAINBACK, 1999). Perceber em cada experiência sua singularidade, leva a descoberta de possibilidades e aprimoramento do processo inclusivo, a inserção da criança com síndrome de Down, na rede regular, deve levar em conta as necessidades de cada criança. Essas considerações, quando não observadas, podem trazer danos à saúde mental do aluno, assim como de seus familiares. Essa afirmação pode ser melhor compreendida por meio da narrativa abaixo:

[...] voltou a regredir, ele começou a fazer xixi na roupa, cocô ta, ele não queria ficar na sala de aula, começou a ficar agressivo com os colegas [...] Ele teve que fazer tratamento, e eu, se eu não tivesse tirado ele na época, na hora nessa época, provavelmente eu também ia ter que fazer tratamento, porque eu saía de lá sempre desidratada, chorando, porque sempre era queixa, sempre era ele sabe? (P3) 
Efetivamente é necessário um discurso crítico quanto aos que defendem, incondicionalmente, as práticas inclusivas, e também a realidade trágica que, muitas vezes, pode ser descrita a partir das práticas cotidianas nas escolas de ensino regular (MARCONDES, 2005). Em seu relato, a mãe P5, amparada por laudos que atestaram danos à saúde mental do filho e pela promotoria pública, conta que o retirou da escola:

"[...] ficou a ponto de não mais querer pegar no lápis, porque ele era burro, e ele não sabia por que a professora tinha dito que ele era burro, e a professora gritava, ele ficou com muito trauma [...] nunca mais se interessou pela alfabetização [...] até hoje ele toma medicação [...]”.

A tentativa de resolver os problemas escolares sem levar em consideração as relações, que se estabelecem entre a problemática da criança e o funcionamento institucional, constitui uma solução muito aflitiva para a criança, pois esta se vê convocada a sustentar a loucura da instituição com seu sintoma (MANNONI, 1990 apud SILVA, 2006). O ambiente escolar deve estar imbuído em propiciar à criança incluída um desenvolvimento acadêmico e social de qualidade, isso leva a necessidade de rever as fragilidades do processo, principalmente àqueles fatores que são considerados nocivos à saúde mental dos envolvidos, como por exemplo, exigências demasiadas que podem levar ao stress, dificuldades dos recursos humanos na habilidade de mediar as diferenças, entre outras.

Sobre isso a mãe (P4) refere que para ela, a inclusão vai além de normas e leis, de instalações físicas adequadas e de ajustes na formação do professor; do número de alunos em sala de aula, da necessidade de auxiliar na classe. A questão fundamental para essa mãe "[...] com certeza passa por coração, sabe? De tratar como um ser humano, [...] ah, isso eu não preciso nem ter um filho Down pra fazer para os outros" (P4). Desmobilizar as barreiras que inviabilizam a inclusão, na visão dessa mãe, passa pela sensibilidade: atributo necessário para se envolver e criar condições satisfatórias de convívio e aprendizagem nos ambientes escolares. O exposto vai ao encontro dos resultados encontrados no estudo de Padilha (2013) sobre a inclusão de crianças com deficiência física, neles a autora destaca que a inclusão escolar não se limita ao aspecto didático-pedagógico, mas envolve os aspectos de acolhimento afetivo e social.

\section{III - Contribuições e dificuldades do processo de inclusão nas escolas regulares \\ O paradigma inclusivo refere à responsabilidade com a educação de todos.} Portanto, todas as escolas regulares estariam atualmente enquadradas como inclusivas e, consequentemente, comprometidas em contribuir com ações que satisfaçam as necessidades de cada aluno na sua singularidade (SEKKEL; CASCO, 2008). Porém, o relato das participantes revelam uma escola ainda despreparada para a inclusão.

"[...] olha mãe, tu pode até matricular a tua filha aqui, só que assim, a gente não pode te prometer qualidade, vai ser mais uma né" (P2). Não, não, a não, nós já temos uma criança com síndrome de Down. Ah não é muito difícil, [...] coloquei que iria 
conversar com a Diretora né, da escola, ela disse: “'Ah, mas não adianta falar porque é muito difícil, a gente já tem um, e não pode ter outro." (Pl)

Para Rodrigues (2008, p. 13), "se a diferença é identificada com o que é insuficiente, com o que é negativo e particular, é natural que as diferenças surjam como um contratempo e uma dificuldade". A falta de observação, às leis de inclusão, coloca as mães em situações de desamparo. Sendo assim, a oportunidade de escutá-las leva ao conhecimento do tipo de dificuldades a que estão submetidas: "Apesar do que já existe de leis e de amparo público, mas a gente continua pedindo esmolas, né”. (P4)

"Na televisão as leis são muito bonitas. Inclusão! Inclusão! Mas tu vai vive a realidade é totalmente diferente. E a questão do portador da síndrome de Down [...] ela tem uma deficiência mental né, é diferente de uma criança com deficiência física, que a cabeça é boa, que eles conseguem aprender". (P5)

Uma característica marcante da síndrome de Down, a limitação na capacidade intelectual, pode representar um fator negativo, que dificulta a permanência dessas pessoas no sistema regular de ensino. A participante P3 questiona os benefícios da inclusão para as pessoas com síndrome de Down:

“[...] então é as limitações mentais mesmo que dificultam, tem que ter uma pessoa mais ao lado ali, ajudando, orientando, talvez pra ele não se sentir assim, isolado, ou então ta lá dentro da sala de aula, mas ta fazendo o quê? Ta incluído? É inclusão fica lá dentro só pra conviver".

[...] ele se sentia o bobinho da corte lá dentro da escola sabe? Os outros falando uma linguagem e ele outra. Que ele falava assim: Mãe o que é geografia? Ele nem sabia o quê que era geografia! Mãe o que que é história? Então ele não sabia o que tavam falando, pra ele, era uma outra língua, e ele tava ali perdido sabe? (P3)

A maioria das mães apontam a necessidade de um professor(a) auxiliar, que possa ajudar o professor(a) titular, porque sozinho se torna difícil o que leva este profissional a priorizar a aprendizagem da maioria dos alunos, ou seja, crianças sem deficiência. Quem ilustra essa dificuldade é a mãe P4."[...] o professor com 26, 27 e 28 alunos [...] não vai trabalhar só com um, para ter 27 reclamando dele, então ele prefere deixar de lado esse um e manter os outros 27 [...]". Embora este um ocupe o mesmo espaço que os alunos ditos normais, pode ficar invisível aos educadores. "A inclusão como vem ocorrendo nas práticas escolares pode ser perversa e danosa à subjetividade da criança, na medida em que oportuniza a invisibilidade do aluno segregado" (SMEHA; SEMINOTTI, 2008, p. 81)

Sobre fatores que favorecem, a mãe P2 relata que, embora decepcionada e frustrada com a escola, vê como favorável a questão da inclusão, porque “[...] eles tão ali convivendo e as pessoas vão conhecendo, vão vendo que eles têm as limitações, mas mesmo assim são seres que têm sentimentos, que têm afetividade". Pl traz que a inclusão "favoreceu porque ele está aprendendo com as outras crianças". A importância da inclusão fica refletida nos comentários dessas mães que estão no início da caminhada 
inclusiva nas escolas regulares. P2 fala da maior contribuição da inclusão, a socialização dessas crianças, que o isolamento das classes especiais não oportunizavam, além de propiciar as outras crianças saber "[...] que têm outros seres, com dificuldades, com limitações".

De outro modo, a mãe P4 aponta como contribuição a própria lei de inclusão: "Olha, eu acho que a lei veio favorecer sim. Se não tivesse lei, nosso filho não pisava na porta de uma escola pública né".

Eu acho que a escola pega, tem que fazer inclusão, mas ela não sabe como e não se prepara nunca, porque faz quantos anos, né. A história vai se arrastando, e eles ficam sem compromisso e não têm o compromisso de dar uma resposta [...] meu filho estuda nessa escola desde os seis anos, ele ta com 16, faz dez anos e até agora ninguém sabe trabalhar, ninguém sabe dar uma resposta, entendeu? (P4)

Embora o ambiente escolar deva contribuir para o desenvolvimento das crianças incluídas, a falta de conhecimento e comprometimento pode se relacionar como infere a mãe P4 da obrigatoriedade da lei de inclusão. Para Mantoan (2002), entretanto, a quebra do igual e o advento da diversidade, nas escolas regulares, devem fazer do professor um profissional atento à singularidade de cada integrante do grupo, sendo um promotor do intercâmbio entre os pares singulares, dentro de espaços que não se caracterizam mais como homogêneos. Nesse sentido, Garcia (2013) faz reflexões acerca da formação docente no âmbito das políticas inclusivas, a autora aponta críticas à formação funcional e superficial de docentes com pouca qualificação teórica e pedagógica, modelo que ratifica os valores de uma sociedade capitalista.

A maioria das mães referiram dificuldades, mas suas preocupações encontram ideias que podem contribuir para o êxito do processo, o autor abaixo afirma:

O projeto inclusivo se faz a partir do momento em que você conhece a criança e sua família. É preciso saber com quem se está lidando, ter uma idéia da questão subjetiva da criança. Qual é o problema que está acontecendo com essa criança? Quais são as potencialidades e dificuldades que ela tem? Laudos são importantes, porém o que vai pesar são os aspectos subjetivos singulares de cada caso. O que vale é aquilo que se conhece da criança. (RANÑA, 2005, p. 91)

As mães preocupadas com o ensino de seus filhos exigem que a inclusão aconteça com eficácia nas escolas. Assim, elas manifestam suas insatisfações diante de uma realidade, na qual as escolas públicas não conseguem avançar na consolidação da inclusão, ao contrário, muitas vezes tornam-se palco de uma exclusão velada e invisível, mascarando a diferença em busca de uma suposta normalização do aluno com deficiência. O que pode ser ainda mais prejudicial ao desenvolvimento psíquico de uma criança do que não pertencer à escola dos normais. 


\section{Considerações finais}

A educação para todos trouxe um clima de esperança e progresso no sistema educacional brasileiro. Estava garantido o ingresso na escola regular de pessoas até então segregadas. Porém, os resultados deste estudo apontam contradições entre a proposta estabelecida na política educacional no Brasil e a realidade das escolas públicas. Diante das disparidades entre o que está posto como ideal e o que se realiza na prática, a maioria das mães, que participaram do estudo, percebem o processo como ineficiente e, muitas vezes, nocivo à saúde mental dos filhos. Vivências perturbadoras são provocadas pela não observação daquilo que se acha posto em termos de leis e preceitos inclusivos, o que desperta, nas mães, sentimentos de mágoa, tristeza e frustração. A difícil caminhada que as mães e seus filhos enfrentam faz com que algumas desistam no meio desse caminho.

Danos à subjetividade dos filhos são apontados pelas mães, e inferidos a práticas educativas equivocadas àqueles com deficiência intelectual. Por ser esta uma característica presente na síndrome de Down, os fatos sinalizam que não se comprova a incondicionalidade do benefício inclusivo a todos. Cabem, portanto, nessa questão, a dúvida e a indicação de uma pesquisa longitudinal com crianças que participam da experiência inclusiva, o que traria mais conhecimento sobre as repercussões da inclusão na construção subjetiva dessas crianças.

Por não ser possível refutar o que está posto pelas mães, mas também por entender a complexidade que atravessa esse sistema que se diz inclusivo, conclui-se que uma solução única não pode ser apontada, pois a escola se constituiu historicamente e, ainda, se apresenta como uma instituição excludente. Dar conta, porém, de incluir o estigmatizado, o diferente, o desviante da norma é um desafio para a construção de uma sociedade mais justa, que ofereça oportunidade de uma boa escolarização para todas as crianças. O desafio ainda é maior ao considerar que, o atual cenário da escola pública no Brasil, apresenta problemas nos aspectos que envolvem a qualidade do ensino, a formação de educadores e o pouco investimento no setor da educação.

Embora os dados tenham saturado numa amostra de cinco mães, entende-se que o estudo é insuficiente para mapear as diversas experiências que se apresentam nos ambientes inclusivos. Considera-se a importância de, futuramente, ampliar o público alvo da pesquisa, ouvindo também os alunos, professores e demais envolvidos nesse processo. Dar voz, portanto, àqueles que vivenciam a experiência de inclusão escolar é imprescindível para a compreensão do fenômeno, sendo ele atravessado por questões históricas, políticas e econômicas, entre outras. Superar os limites e efetivamente incluir os alunos com síndrome de Down; passa pelo compromisso de descobrir e organizar ações que atendam às necessidades singulares de crianças com deficiência intelectual.

\section{Referências}

BARDIN, L. Análise de conteúdo. Lisboa, Portugal: Ediçōes 70, 2002.

CARVALHO, F. Reflexões em torno da inclusão em contexto educativo. In: FREITAS, S. N. (Org.). Tendências Contemporâneas de Inclusão. Santa Maria: Ed. da UFSM, 2008. p. 31- 47.

Revista Educação Especial | v. 27 | n. 49 | p. 403-416| maio/ago. 2014

Santa Maria 
CASTRO, S. F. de; FREITAS, S. N. As Representações Sociais dos Professores de Alunos com Síndrome de Down Incluídos nas Classes Comuns do ensino Regular. In: FREITAS, S. N. (Org.). Tendências Contemporâneas de Inclusão. Santa Maria: Ed. da UFSM, 2008. p. 49-76.

CUNHA, M.I. O bom professor e a sua prática. Campinas: Papirus, 1989.

EMÍLIO, S. A; CINTRA, F. M. Sobre Abismos e Pontes: Entre a Inclusão Desejável e a Possível. In: FRELLER, C.; FERRARI, M. A. L. D., SEKKEL, M. C. (Orgs.). Educação Inclusiva: percursos na educação infantil. São Paulo: Casa do Psicólogo, 2008. p. 80-92.

GARCIA, R. M. C. Política de educação especial na perspectiva inclusiva e formação docente no Brasil. Revista Brasileira de Educação v. 18 n. 52 jan.-mar. 2013.

GIL, A. C. Métodos e técnicas de pesquisa social. São Paulo, SP: Atlas, 2006.

KASSAR, M. C. M. Educação especial na perspectiva da educação inclusiva: desafios da implantação de uma política nacional. Educar em Revista, Curitiba, n. 41, p. 61-79, jul./set. 2011.

KASSAR, M. C. M. Educação especial no Brasil: desigualdades e desafios no reconhecimento da diversidade. Educ. Soc. , Campinas, v. 33, n. 120, p. 833-849, jul./set. 2012.

MANTOAN, M. T. E. A Construção da Inteligência nos deficientes mentais: um desafio, uma proposta. Revista Brasileira de Educação Especial, v. 1, n. 1, p. 107-114, 1992.

. Ensinando a Turma Toda. Pátio: Revista Pedagógica, Artmed. Ano V, n. 20, p. 18-23, fev./abr.2002.

Caminhos Pedagógicos da Educação Inclusiva. In: GAIO, R. ; MENEGUETTI, R. G. K. (Orgs.). Caminhos Pedagógicos da educação especial. Petrópolis: Vozes, 2004. p. 79-94.

Inclusão escolar: o que é? por quê? Como fazer? 2. ed. São Paulo: Moderna, 2006.

MARCONDES, A. Articulação da Saúde com a Educação nos Desafios da Educação Inclusiva. In: MACHADO, A. , M. et al. Psicologia e Direitos Humanos: educação inclusiva, direitos humanos na escola. São Paulo: Casa do Psicólogo, 2005, p. 71-82.

MINAYO, M. C. S. O Desafio da Pesquisa Social. In: DESLANDES, S. F. ; GOMES, R. (Org.). Pesquisa Social: Teoria, método e criatividade. 27. ed. Petrópolis: Vozes, 2008. p. 9-29.

OMOTE, S. A concepção de deficiência e a formação do profissional em educação Especial. In: MARQUESINE, M. C.(Org.) Perspectivas multidisciplinares em educação especial II. Londrina: Ed. UEL, 2001. p. 45-64.

PADILHA. A. C. A educação infantil e a criança com deficiência: desafios e Possibilidades. Rev. educ. PUCCamp Campinas, v. 18, n. 1,p. 55-63, 2013.

PIRES, J. A questão Ética frente as diferenças: uma perspectiva da pessoa como valor. In: MARTINS, L. A. R. et al. Inclusão: compartilhando saberes. Petrópolis: Vozes, 2008. p. 78-94.

RANÑA, W. Direitos humanos, educação inclusiva e reforma psiquiátrica para a criança e o adolescente. In: MACHADO, A. , M. et al. Psicologia e Direitos Humanos: educação inclusiva, direitos humanos na escola. São Paulo: Casa do Psicólogo, 2005. p. 83-97.

SANTOS, N. A. S.; MENDES, E. G. A inclusão de Alunos com Deficiência na Escola Regular: Algo de Novo no Front. In: MARQUESINE, M. C. (Org.) Perspectivas multidisciplinares em educação especial II. Londrina: Ed. UEL, 2001. p. 127-135.

SEKKEL, M. C.; CASCO, R. Ambientes Inclusivos para a Educação Infantil: Considerações sobre o Exercício Docente. In: FRELLER, C.; FERRARI, M. A. L. D.; SEKKEL, M. C. (Orgs.). Educação Inclusiva: percursos na educação infantil. São Paulo: Casa do Psicólogo, 2008. p. 19-37.

SILVA, I.C. Educação e Diferenças: Algumas das Contribuições da Experiência de Maud Mannoni. In: GURSKI, R. (Org.). Cenas da infância atual: a família, a escola e a clínica. Ijuí: Ed.Unijuí, 2006. p. 115-121.

STAINBACK, S. ; STAINBACK, W. Inclusão: Um Guia para educadores. Trad. Magda F. Lopes. Porto Alegre: Artes Médicas Sul, 1999.

SMEHA, L. N.; SEMINOTTI, N. Educação Inclusiva: perspectivas da diferença no grupo de alunos. Revista Educação. Centro de educação, Universidade Federal de Santa Maria, v. 33, n. 2, p. 305-322, 2008.

UNESCO. CONFERÊNCIA MUNDIAL DE EDUCAÇÃO ESPECIAL. Declaração de Salamanca. 1994. Disponível em: ‘http://portal.mec.gov.br/seesp/arquivos/pdf/salamanca.pdf`. Acesso em: 06 abr. 2009. 
VEIGA NETO, A. Quando a inclusão pode ser uma forma de exclusão. In: MACHADO, A. M. et al. Psicologia e Direitos Humanos: educação inclusiva, direitos humanos na escola. São Paulo: Casa do Psicólogo, 2005. p. 55-70.

VOIVODICK, M. A. Inclusão escolar de crianças com Síndrome de Down. Petrópolis: Vozes, 2004.

\section{Correspondência}

Luciane Najar Smeha - Centro Universitário Franciscano, Área de Ciências da Saúde, Curso de Psicologia. Rua dos Andradas, 1614, Centro, CEP: 97010-032, Caixa-postal: 851 - Santa Maria, Rio Grande do Sul - Brasil.

E-mail:lucianenajar@yahoo.com.br

Recebido em 19 de julho de 2013

Aprovado em 2 de abril de 2014 